\title{
Relationships between Tree Vigor Indices and a Tree Classification System Based upon Apparent Stem Defects in Northern Hardwood Stands
}

\author{
Edouard Moreau ${ }^{1}$, Steve Bédard ${ }^{2}$, Guillaume Moreau ${ }^{1}$ and David Pothier ${ }^{1, * \mathbb{D}}$ \\ 1 Centre d'étude de la forêt, Département des sciences du bois et de la forêt, Pavillon Abitibi-Price, \\ 2405 rue de la Terrasse, Université Laval, Québec, QC G1V 0A6, Canada; \\ edouard.moreau1@gmail.com (E.M.); guillaume.moreau.3@ulaval.ca (G.M.) \\ 2 Direction de la recherche forestière, Ministère des Forêts, de la Faune et des Parcs du Québec, \\ 2700 rue Einstein, Québec, QC G1P 3W8, Canada; steve.bedard@mffp.gouv.qc.ca \\ * Correspondence: david.pothier@sbf.ulaval.ca; Tel.: +1-418-656-2131 (ext. 12908)
}

Received: 10 September 2018; Accepted: 18 September 2018; Published: 21 September 2018

\begin{abstract}
Many northern hardwood stands include several low-vigor trees as a result of past management. To restore these degraded stands, partial cuts are applied with partly validated tree classification systems that are based upon apparent stem defects. We sampled 214 sugar maple (Acer saccharum Marsh.) and 84 yellow birch (Betula alleghaniensis Britt.) trees from six sites covering the northern hardwood forest zone of the Province of Quebec, Canada. We evaluated their vigor with a four-class system, and quantified the growth efficiency index and several indices that were based solely upon radial growth. The growth efficiency index increased non-significantly with increasing tree vigor class. The five-year basal area increment $\left(\mathrm{BAI}_{-1-5}\right)$ was significantly different between the lowest and highest tree vigor classes. Yet, temporal changes in $\mathrm{BAI}_{-1-5}$ helped classify correctly only $16 \%$ of high-vigor trees that became poorly vigorous $8-10$ years later. Overall, these results suggest that the tree classification system is weakly related to actual tree vigor and its application likely generates few significant gains in future stand vigor. Modifying and simplifying the tree vigor system must be considered to facilitate the tree marking process that is required to improve the vigor of degraded stands.
\end{abstract}

Keywords: sugar maple; yellow birch; tree vigor; growth efficiency index; tree selection

\section{Introduction}

Northern hardwood forests cover large areas of southeastern Canada and the northeastern USA, from the Great Lakes region to the Atlantic Ocean. These forest ecosystems have considerable socio-economic importance because they are located near densely populated areas and are composed of valuable tree species that are used by the appearance wood-products industry [1,2]. The traditionally high demand for these high-value products (veneers, flooring and furniture, among others) has long led to the application of diameter-limit cuts, which are aimed at mainly harvesting trees with high-quality saw logs [3]. Several decades of selection that is biased towards the most valuable trees within a stand, an unsustainable practice that is also known as 'high-grading', has resulted in large areas being covered by degraded, low-vigor forest stands [4-6].

In 2005, a new tree-vigor classification system was introduced in the Province of Quebec, Canada $[1,2,7]$. The system was implemented with the clear objective of restoring the overall vigor of degraded hardwood stands by prioritizing the harvesting of low-vigor trees in partial cut operations [1]. To achieve this objective, the classification system defined tree vigor as the risk of mortality during the upcoming cutting cycle (i.e., a 25-year period), based upon the presence or absence of precursors 
for wood decay and other tree defects [1,2]. Although this four-class tree-vigor system is based upon an extensive knowledge of forest pathology [7], its further application requires empirical validation. Among the studies that have attempted to realize such validations, Fortin et al. [8] and Guillemette et al. [9] observed that mortality risk of the lowest tree-vigor class was effectively higher than that of the other classes, while these other classes were only slightly different from one another. Furthermore, Hartmann et al. [10] observed that differences in radial growth occurred between the lowest and highest classes of vigor, without observing any differences between these extremes and the two intermediate classes. Overall, these results would suggest that this tree classification system might not achieve the intended purpose because its inherent complexity would not warrant its widespread application, given its lack of desired accuracy.

To obtain a better overview of the application potential of classification systems that are based upon apparent stem defects, validation using a proven quantitative tree vigor index would be appropriate. The growth efficiency index [11] appears to be suitable for this purpose since it corresponds to the ratio of annual stemwood production, which is one of the last priorities of tree resource allocation [12], to tree leaf area, which represents tree carbon acquisition. Therefore, a low value of this index indicates that most of the acquired carbon is used to sustain high priority allocations such as shoot and root growth, and little is left for stemwood production and defensive compounds [12]. Thus, trees associated with a low growth efficiency index should be poorly vigorous and more prone to mortality. Accordingly, the growth efficiency index is recognized as a reliable tree vigor index [13] and has been successfully used to study tree mortality [12] and stand growth dynamics [14]. In addition, this index has efficiently predicted the vigor of lodgepole pine (Pinus contorta Douglas) [15-17] and sugar maple (Acer saccharum Marshall) [18] trees, together with the probability of mortality of balsam fir (Abies balsamea (L.) Miller) in relation to insect defoliation [19], and the response of conifer stands to commercial thinning [20].

Because calculation of the growth efficiency index requires the estimation of tree leaf area, its use for retrospective tree vigor evaluations is difficult. Such retrospective evaluations are more easily achieved using indices that are based upon growth-ring analysis [10]. Accordingly, such growth-based indices are widely used and recognized as good indicators of tree vigor (e.g., [10,21-24]). Therefore, it would be relevant to establish the degree of agreement between the growth efficiency index, indices that are based solely on tree growth, and tree vigor classes that have been deduced from apparent stem defects.

The general objective of this study was to validate a tree classification system that was based upon apparent stem defects by using two types of tree vigor indices. In agreement with this objective, we stated three hypotheses: (1) growth efficiency index values increase with increasing tree vigor class; (2) temporal decreases in tree vigor class are paralleled by similar decreases in growth-base indices; and (3) tree and stand state variables are adequate predictors of the growth efficiency index. To test these hypotheses, we used a large sample of sugar maple and yellow birch (Betula alleghaniensis Britton) trees, within which vigor classes were evaluated twice on several individuals at intervals of 8 to 10 years. The results of this study could help improve tree selection for partial cutting with a goal of increasing the overall vigor of degraded northern hardwood stands.

\section{Materials and Methods}

\subsection{Study Sites}

Trees were sampled in six sites that were distributed across the northern hardwood zone of the Province of Quebec, Canada. Three sites were located on public lands (Mont-Laurier: $46^{\circ} 39^{\prime} \mathrm{N}^{\prime} 75^{\circ} 38^{\prime}$ W; Duchesnay: $46^{\circ} 39^{\prime} \mathrm{N}, 75^{\circ} 38^{\prime} \mathrm{W}$; and Biencourt: $48^{\circ} 01^{\prime} \mathrm{N}, 68^{\circ} 30^{\prime} \mathrm{W}$ ), while the three others were located on private woodlots $\left(45^{\circ} 28^{\prime}-46^{\circ} 28^{\prime} \mathrm{N}, 70^{\circ} 20^{\prime}-71^{\circ} 45^{\prime} \mathrm{W}\right)$ that are owned by Domtar Corporation (Montreal, QC, Canada) (Figure 1). 


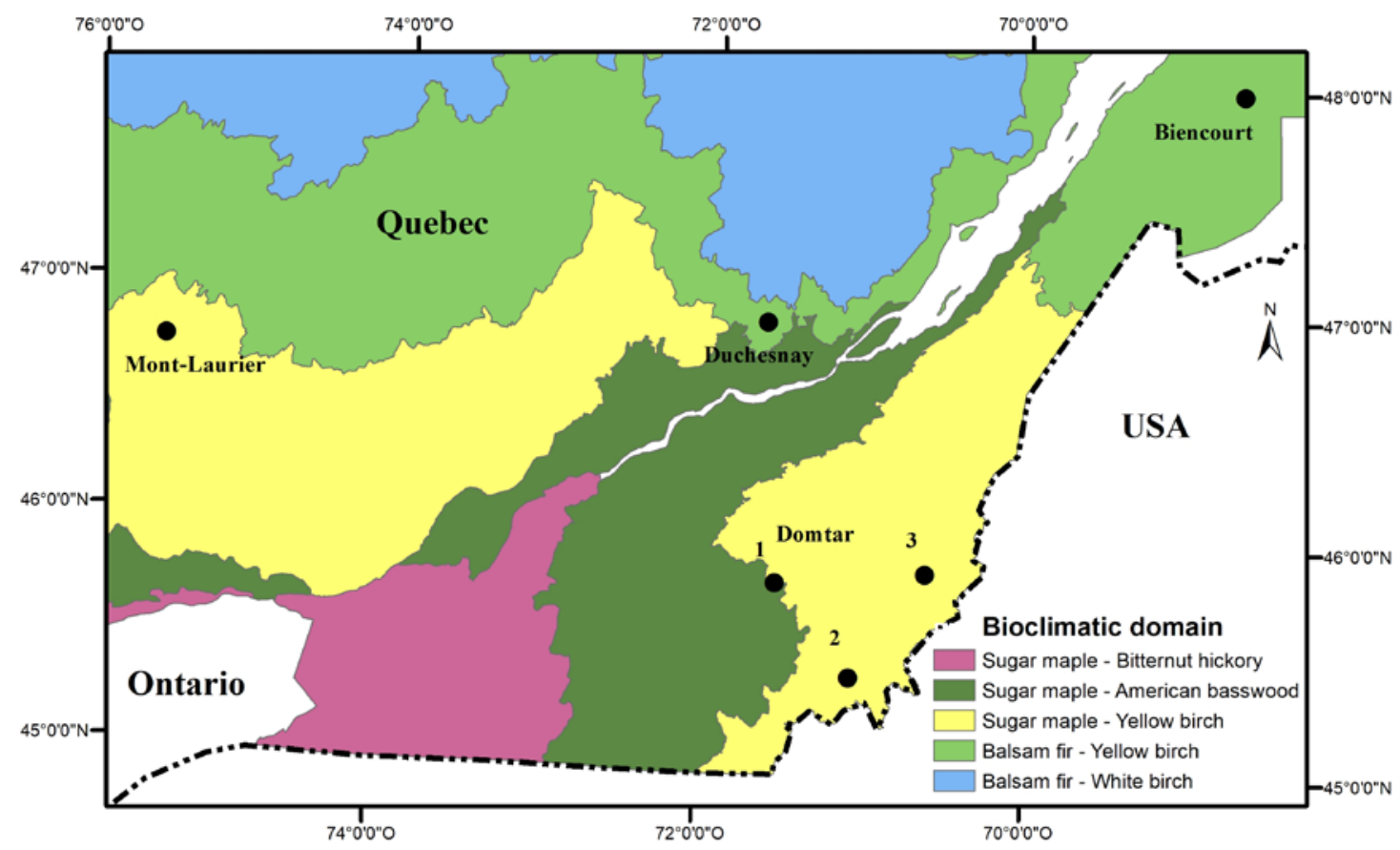

Figure 1. Locations of the six study sites in northern hardwood forests of Quebec.

The Mont-Laurier site lies within the sugar maple-yellow birch bioclimatic domain, whereas the Duchesnay and Biencourt sites are part of the balsam fir-yellow birch bioclimatic domain [25]. Two sites that were located on the private woodlots of Domtar (sites Domtar 2 and 3, Figure 1) are also part of the sugar maple-yellow birch bioclimatic domain, while the third privately owned site (site Domtar 1, Figure 1) is part of the sugar maple-American basswood (Tilia americana L.) bioclimatic domain. The latter is characterized by mean annual temperatures between 4 and $5{ }^{\circ} \mathrm{C}$, and mean annual precipitation ranging between 1000 and $1150 \mathrm{~mm}$; the length of the growing season ranges from 160 to 190 days. The sugar maple-yellow birch domain is characterized by mean annual temperatures between 2.5 and $5{ }^{\circ} \mathrm{C}$, and mean annual precipitation between 950 and $1100 \mathrm{~mm}$, with a growing season of 160-180 days. The balsam fir-yellow birch domain is characterized by mean annual temperatures between 1.5 and $2.5^{\circ} \mathrm{C}$, and mean annual precipitation between 900 and $1100 \mathrm{~mm}$, with a growing season of 160-170 days [25]. The topography of all sites is characterized by hills and an average slope of $15^{\circ}$, with main surface deposits composed of shallow or deep tills [26]. The study sites were covered by naturally established, uneven-aged stands that were mainly composed of sugar maple, yellow birch and red maple (Acer rubrum L.), with minor components of American beech (Fagus grandifolia Ehrhart), balsam fir, and red spruce (Picea rubens Sargent).

\subsection{Tree Sampling}

The Mont-Laurier and Biencourt sites were sampled respectively in 2010 and 2011, while trees from the Duchesnay site were first sampled in 2007 and 2008, and a second time in 2016. In these three sites, trees were individually selected to cover a broad range of diameter and vigor classes. Trees from the three Domtar sites were located in permanent sample plots $\left(400 \mathrm{~m}^{2}\right)$ that were first measured in 2006 and a second time in 2016. In total, we sampled 154 trees (91 sugar maple (sM) and 63 yellow birch (yB) trees) from Duchesnay, 31 (31 sM) from Mont-Laurier, 30 (30 sM) from Biencourt, 19 (11 sM, $8 \mathrm{yB}$ ) from Domtar 1, 33 (20 sM, $13 \mathrm{yB})$ from Domtar 2, and 31 (31 sM) from Domtar 3. The number of sampled trees decreased with increasing diameter class, consistent with the negative exponential distribution that is typical of uneven-aged stands (Table 1). 
Table 1. Number of trees that were sampled at the six sites by diameter class at breast height $(\mathrm{DBH}, 1.3 \mathrm{~m})$ and tree vigor class

\begin{tabular}{cccccc}
\hline DBH $(\mathbf{c m})$ & M & S & C & R & Total \\
\hline $20-29.9$ & 29 & 13 & 39 & 29 & 110 \\
$30-39.9$ & 16 & 20 & 28 & 28 & 92 \\
$40-49.9$ & 15 & 16 & 21 & 20 & 72 \\
$50-59.9$ & 6 & 9 & 7 & 2 & 24 \\
Total & 66 & 58 & 95 & 79 & 298 \\
\hline
\end{tabular}

In each sampling year, we recorded the diameter at breast height $(\mathrm{DBH} ; \pm 0.1 \mathrm{~cm})$, the vigor class, the total height and the height at the base of the live crown $( \pm 0.1 \mathrm{~m})$ of each tree. We also measured crown radii $( \pm 0.01 \mathrm{~m})$ along the four cardinal directions $(\mathrm{N}, \mathrm{E}, \mathrm{S}$, and $\mathrm{W})$ from the centre of the bole to the edge of the crown using vertical sighting [27]. Increment cores that were sampled at $1.3 \mathrm{~m}$ above ground level were then air-dried and progressively sanded down to allow a clear identification of growth rings. Ring widths were measured using a Velmex micrometer $( \pm 0.002 \mathrm{~mm})$ and were corrected to take into account radial shrinkage during drying.

\subsection{Tree Vigor Classification}

We evaluated tree vigor with a four-class system, which is assumed to be related to the probability of tree mortality over the next 25-year period [28]. As described by Delisle-Boulianne et al. [1], the distinction among classes is based upon the presence and severity of certain types of defects. These are grouped into eight categories: (1) conks and stromata; (2) cambial necrosis; (3) stem deformations and injuries; (4) stem base and root defects; (5) stem and bark cracks; (6) woodworms and sap wells; (7) crown decline; and (8) forks and pruning defects. Dichotomous keys that are based upon these various defects can be used to assign any tree to one of the four following classes: Class $\mathrm{M}$ corresponds to trees with major defects that will likely die during the next 25-year period; Class $S$ refers to trees with major defects that are thought to not compromise their likelihood of survival in the medium term; Class $\mathrm{C}$ includes trees with some minor defects and that are still growing; and Class $\mathrm{R}$ is composed of trees that are almost defect-free that should be preserved for the future.

\subsection{Vigor Indices}

To examine relationships between the vigor classes that were based on apparent stem defects and quantitatively measured indices, we used four growth indices of which one was based on tree growth per unit leaf area, while the remaining three were solely based on tree diameter measurements.

\subsubsection{Growth Efficiency Index}

The growth efficiency index is defined as the annual production of stemwood per unit leaf area (Waring 1980) [11]. The average stemwood mass that was produced annually by each tree was calculated with the following equation, which has been adapted from Lambert et al. [29]

$$
\Delta W_{s}=\frac{\beta_{1}\left(D_{t}^{\beta_{2}}-D_{t-5}^{\beta_{2}}\right)}{5}
$$

where $\Delta W_{s}$ is the dry mass of stemwood produced annually $(\mathrm{kg}), D_{t}$ is tree DBH in the year of tree vigor class determination $(\mathrm{cm}), D_{t-5}$ is tree $\mathrm{DBH}$ five years prior to tree vigor class determination $(\mathrm{cm})$, which was determined from increment cores, the parameter $\beta_{1}$ takes the empirical value of 0.1315 for sugar maple and 0.1932 for yellow birch, while the value of $\beta_{2}$ is 2.3129 for sugar maple and 2.1569 for yellow birch [29]. The leaf area of each tree was estimated with an equation that was developed by Moreau et al. [30]

$$
L A=\beta_{1} C S A^{\beta_{2}}
$$


where $L A$ is tree leaf area $\left(\mathrm{m}^{2}\right), C S A$ is crown surface area $\left(\mathrm{m}^{2}\right)$, which corresponds to the area of the geometric shape of sugar maple and yellow birch crowns (calculated with crown height and mean quadratic radius-Moreau et al. [30]), $\beta_{1}$ is 1.121 for sugar maple and 1.021 for yellow birch, and $\beta_{2}$ is 0.981 for sugar maple and 1.035 for yellow birch. The average stemwood mass produced annually $\left(\Delta W_{s}\right)$ and tree leaf area $(L A)$ were then used to calculate the growth efficiency index (GE) of each tree as

$$
G E=\Delta W_{s} / L A
$$

\subsubsection{Indices Solely Based upon Tree Diameter Measurements}

All indices that were solely based upon tree diameter measurements were calculated to correspond to the two years of tree vigor class determination, and for periods $\Delta t$ of $3,5,7$, and 10 years prior to the year of tree vigor class determination. We tested three index types and each of them was calculated for the four $\Delta t$ periods, for a total of 12 calculated indices. The first index type corresponds to the basal area increment (BAI) of trees that was calculated for each $\Delta t$. The second index type is a relative BAI, i.e., the ratio between the BAI of a tree for a given $\Delta t$ and the basal area at the beginning of the period under consideration. The third index type is a ratio between the BAI of a tree for a given $\Delta t$ and the BAI for an equivalent $\Delta t$ that preceded the first $\Delta t$ under consideration. This last index type indicates whether BAI is increasing $(>1)$ or decreasing $(<1)$. For example, if tree vigor class was determined in 2016 and $\Delta t$ was three years, the first index type would correspond to the BAI that was calculated from 2013 to 2015, the second index type to the ratio between the BAI calculated from 2013 to 2015 and the tree basal area in 2012, and the third index type to the ratio between the BAI calculated from 2013 to 2015 and the BAI from 2010 to 2012.

\subsection{Statistical Analysis}

All analyses were performed in the R statistical environment (version 3.3.2, R Development Core Team 2016, Vienna, Austria). Model assumptions (homogeneity of variance and normality of residuals) were validated using Levene and Shapiro-Wilk tests, together with graphical analysis of the residuals.

To test the first hypothesis, which relates the growth efficiency index to tree vigor classes, we fitted a linear mixed model using the function lme in the nlme package [31]. This model included tree species as a fixed effect and site as a random effect. The growth efficiency index was $\ln$-transformed to achieve normality of the residuals. The analysis was performed using all trees that were sampled from the six sites.

For the second hypothesis, which predicts that decreases in tree vigor classes are associated with similar decreases in growth-based indices, we used four sites for which two determinations of tree vigor class were performed, i.e., Duchesnay and the three Domtar sites. In a first step, we identified which growth-based index was most closely related to the growth efficiency index to use it as the best growth-based predictor to represent tree vigor as a continuous variable. This was performed using linear mixed models with the function lme of the nlme package. We compared the models with the Akaike information criterion (AIC), which is a measure of the loss of information that results from using a model to explain a particular variable [32]. As suggested by Mazerolle [33], we compared the models using differences in AIC between each model and the model with the lowest AIC value $\left(\Delta_{i}\right)$. We also computed the AIC weight $\left(W_{t_{i}}\right)$, which is the probability that a model is the best among those models being compared [32], and the coefficient of determination $\left(R^{2}\right)$. In a second step, we used a linear mixed ANOVA model to determine which growth-based index was best related to tree vigor classes (i.e., a categorical variable). The growth-based index that was best related to both growth efficiency index and tree vigor classes was then used to quantify its temporal changes between two qualitative determinations of tree vigor class.

In a third step, we submitted the previously calculated temporal changes in the growth-based index as an explanatory variable in a logistic regression model that was fitted with the function $\mathrm{glm}$ of the stats package. The dependent binary variable of this model (dummy variable) was formed 
using only vigorous trees that were determined at the first vigor evaluation, which either remained vigorous at the second evaluation (coded value $=1$ ) or became non-vigorous at the second evaluation (coded value $=0$ ). Consistent with the results of Delisle-Boulianne et al. [1], we separated individuals into two classes of tree vigor (i.e., vigorous and non-vigorous trees) by grouping tree vigor classes $\mathrm{M}$ and $\mathrm{S}$ to represent non-vigorous trees, and tree vigor classes $\mathrm{C}$ and $\mathrm{R}$ to represent vigorous trees. We used a cut-point approach to convert the continuous probabilities that were produced by the logistic regression into dichotomous results, i.e., non-vigorous vs. vigorous trees. We considered a tree as non-vigorous at the second vigor evaluation if the model predicted a probability that was lower than a predetermined threshold. This threshold was determined at a value where precision and recall were equal [34]. At this cut-point, positive and negative predictions are made in the same proportions as the prevalence of vigorous and non-vigorous trees in the calibration dataset [6].

To test the third hypothesis, which specifies that tree and stand state variables are adequate predictors of growth efficiency index, we fitted linear mixed models using the function lme of the nlme package [31]. These models were fitted to the entire tree sample from the six sites. The considered state variables included tree $\mathrm{DBH}$, height, relative height, crown diameter, and crown surface area as well as stand basal area and density. The models were compared based upon values of AIC, $\Delta_{i}, W_{t_{i}}$, and $R^{2}$.

\section{Results}

\subsection{Relationship between the Growth Efficiency Index and Tree Vigor Classes}

We found no statistical differences in growth efficiency index between sugar maple and yellow birch $(p=0.8829)$, which were grouped together for subsequent analyses. Even though the growth efficiency index values tended to increase with increasing tree vigor class (Figure 2), this relationship was not statistically significant $(p=0.4800)$.

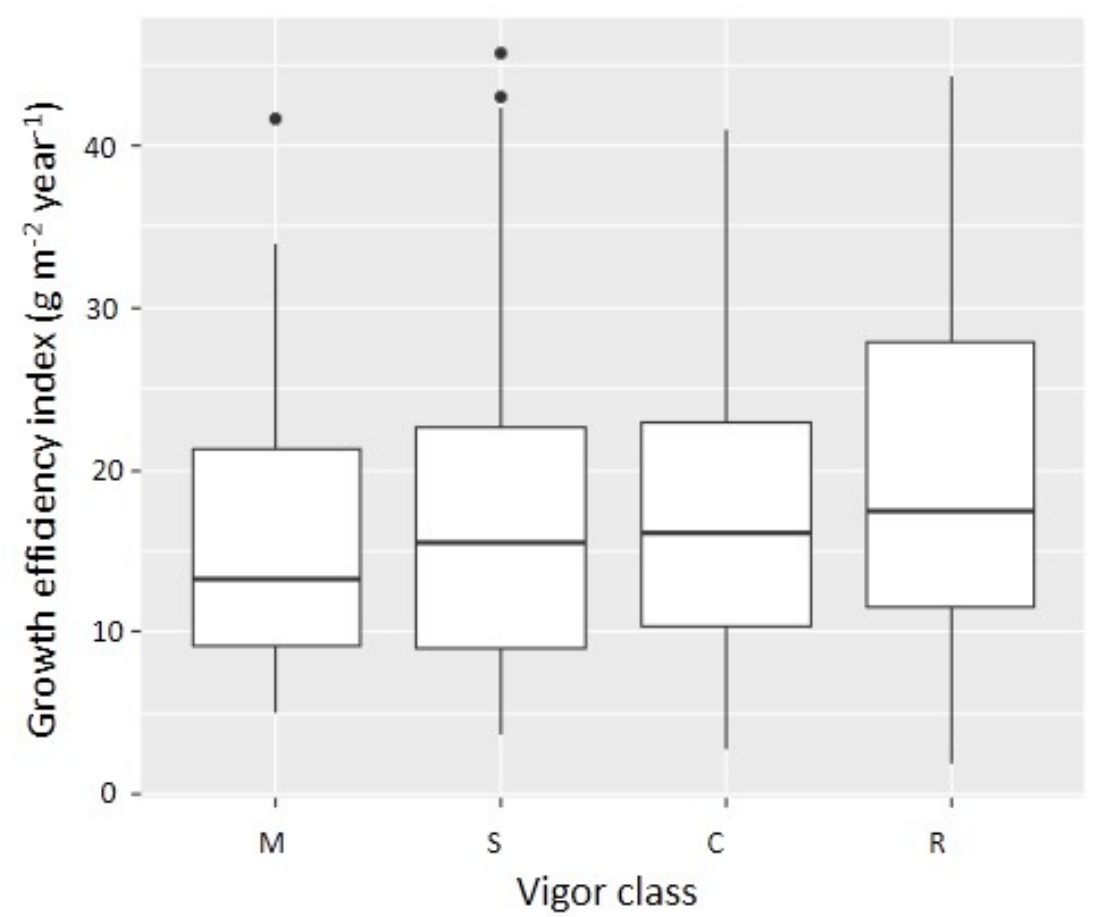

Figure 2. Box-and-whisker plots of the growth efficiency index as a function of tree vigor classes for the combined responses of sugar maple and yellow birch. The bold horizontal line within the boxes corresponds to the median (50th percentile), while the lower and upper limits of the boxes (interquartile range, IQR) represent the 25 th and 75th percentiles, respectively. The whiskers are upper and lower values of $1.5 \times \mathrm{IQR}$, and the individual points are outliers. 


\subsection{Growth-Based Indices and Changes in Tree Vigor Class}

The basal area increment that was calculated over a five-year period $\left(\mathrm{BAI}_{-1-5}\right)$ was the growth-based index that was most closely related to the growth efficiency index (Table 2), and was among the best indices that were related to tree vigor classes (Table 3). This index value was significantly different between the lowest and highest tree vigor classes (i.e., $\mathrm{M}$ and $\mathrm{R}$ classes) at both vigor evaluations ( $p=0.0192$ and $p=0.0009$, respectively), and between the $\mathrm{M}$ and the $\mathrm{C}$ classes at the second vigor evaluation $(p=0.0007)$. Therefore, we included the temporal changes of $\mathrm{BAI}_{-1-5}$ between the two vigor evaluations as an explanatory variable in the logistic regression model to predict the binary tree vigor classes. Validation of this model indicates that $66 \%$ of the trees (i.e., 107 of 161 ) were correctly classified as vigorous or non-vigorous trees (Table 4). Yet, the validation procedure also indicates that only $16 \%$ of trees (i.e., 5 of 32) that became non-vigorous at the second vigor evaluation were correctly classified. The weak capacity of the model to classify correctly vigorous trees that later became non-vigorous is illustrated by the substantial overlapping of BAI $-1-5$ between observed vigorous and non-vigorous trees (Figure 3). This considerable overlap may explain the small range of predicted values of probability that trees remain vigorous, which are all close to the probability threshold (0.78) separating vigorous and non-vigorous trees (Figure 3).

Table 2. Statistics for the best linear mixed models that related the growth efficiency index to different growth-based indices. All models also include an intercept, tree species (the fixed effect), and a random site effect.

\begin{tabular}{ccccc}
\hline Growth-Based Index & AIC & $\boldsymbol{\Delta}_{\boldsymbol{i}}$ & $\boldsymbol{W}_{\boldsymbol{t}_{\boldsymbol{i}}}$ & $\boldsymbol{R}^{2}$ \\
\hline BAI $_{-1-5}$ & 2232.1 & 0 & $9.0 \times 10^{-1}$ & 0.35 \\
BAI $_{-1-7}$ & 2236.5 & 4.5 & $9.6 \times 10^{-2}$ & 0.34 \\
BAI-1-3 $_{\text {BAI }}$ & 2249.3 & 17.3 & $1.6 \times 10^{-4}$ & 0.31 \\
BAI-1-3 $_{\text {-BA-4 }}$ & 2251.0 & 19.9 & $4.2 \times 10^{-5}$ & 0.31 \\
BAI-1-5/BA-6 $^{-3}$ & 2268.2 & 36.2 & $1.3 \times 10^{-8}$ & 0.27 \\
\hline
\end{tabular}

Note: $\mathrm{BAI}$ is the basal area increment, BA is the basal area, AIC is the Akaike information criterion, $\Delta_{i}$ is the difference in AIC between each model and the model with the lowest AIC, $W_{t_{i}}$ is the probability that a model is the best among those being compared, and $R^{2}$ is the coefficient of determination. The subscripts that are associated with growth-based indices correspond to the years during which the variables were computed, with year 0 corresponding to the time of tree vigor evaluation.

Table 3. Results of the analyses of variance (one-way ANOVAs) relating the most relevant growth-based indices to tree vigor classes. All models also included an intercept, the tree species (fixed effect), and a random site effect.

\begin{tabular}{ccccc}
\hline & \multicolumn{2}{c}{ First Vigor Evaluation $(\boldsymbol{n = 2 2 5 )}$} & \multicolumn{2}{c}{ Second Vigor Evaluation $(\boldsymbol{n}=\mathbf{2 9 8})$} \\
\hline Growth-Based Index & $\boldsymbol{F}$ & $\boldsymbol{p}$-Value & $\boldsymbol{F}$ & $\boldsymbol{p}$-Value \\
\hline BAI $_{-1-7}$ & 10.68 & $<0.0001$ & 5.83 & 0.0007 \\
BAI $_{-1-5}$ & 9.56 & $<0.0001$ & 5.83 & 0.0007 \\
BAI-1-10 $_{\text {BAI-1-3 }}$ & 11.63 & $<0.0001$ & 5.73 & 0.0008 \\
BAI $_{-1-7} /$ BA $_{-8}$ & 7.86 & $<0.0001$ & 4.65 & 0.0034 \\
BAI-1-5 $_{\text {BA-6 }}$ & 3.18 & 0.0249 & 5.90 & 0.0006 \\
\hline
\end{tabular}

Note: The two tree vigor evaluations were conducted at intervals of 8 to 10 years on the same trees. 
Table 4. Validation of the model predicting non-vigorous (0) and vigorous (1) trees based upon differences in $\mathrm{BAI}_{-1-5}$ between the two tree vigor evaluations.

\begin{tabular}{ccc}
\hline & Predicted $\mathbf{= 0}$ & Predicted $\mathbf{= 1}$ \\
\hline Observed $=0$ & 5 & 27 \\
Observed $=1$ & 27 & 102
\end{tabular}

Note: All trees were vigorous at the first period of evaluation. A tree was considered to be non-vigorous at the second period of evaluation if the model predicted a probability $p<0.78$. A total of 161 trees were used for the validation operation.

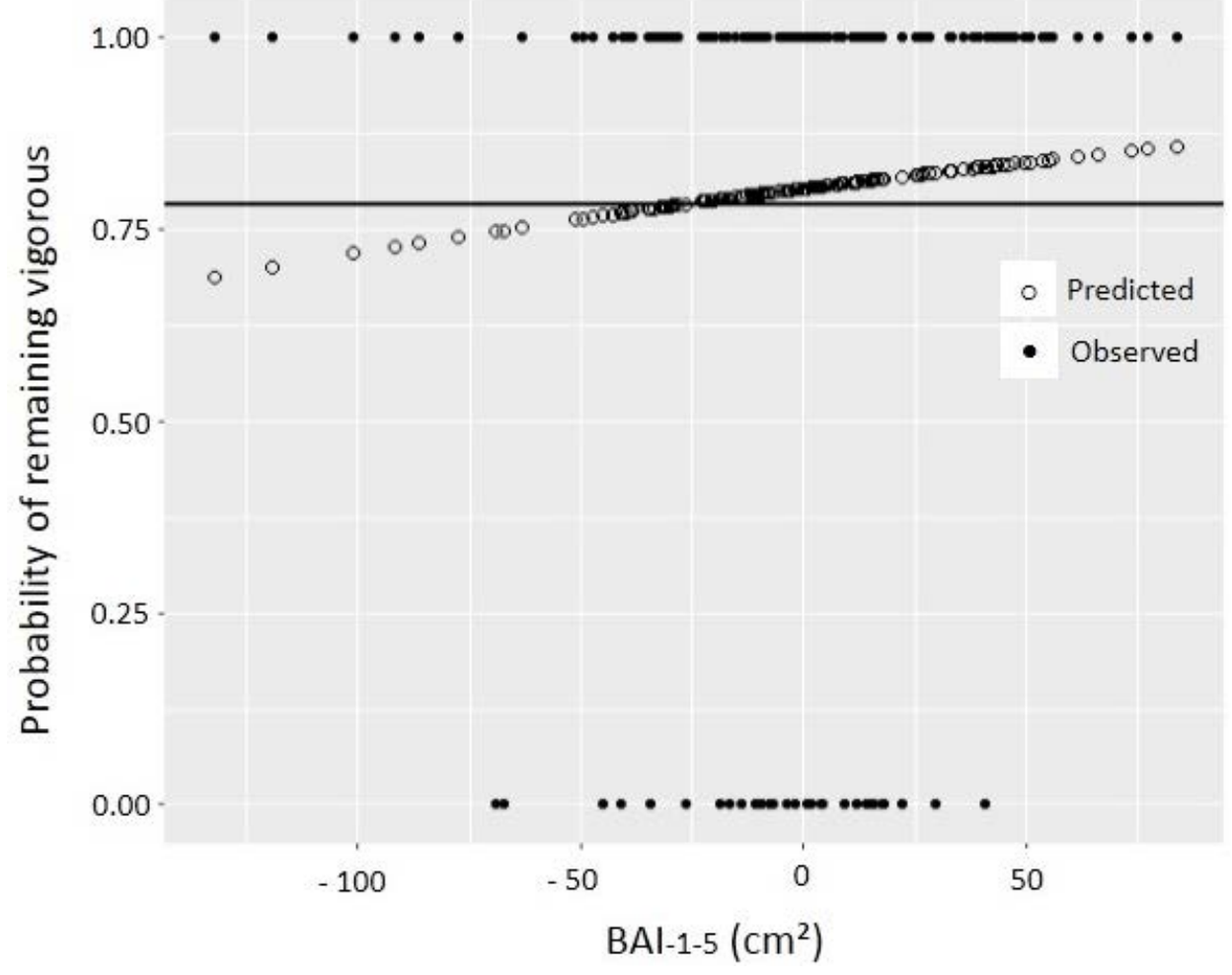

Figure 3. Probability that a vigorous tree at the first evaluation period either becomes non-vigorous (0) or remains vigorous (1) at the second evaluation period as a function of the growth-based index BAI $1-5$. The horizontal line represents the probability threshold (0.78) below which a tree was considered as non-vigorous.

\subsection{Predicting the Growth Efficiency Index}

Based upon AIC values that were calculated from models including various state variables at tree and stand levels, the most parsimonious model predicting the growth efficiency index included only tree relative height, i.e., the height of the tree of interest divided by the height of the tallest tree in a stand (Table 5). However, the predictive ability of this model was rather poor, with a $R^{2}$ of only 0.05 . When the same state variables were related to the three most relevant growth-based indices, the most parsimonious models included tree crown surface area and relative height. Although, the predictive abilities of these models were higher than that of the preceding one, with $R^{2}$ varying from 0.37 to 0.39 , both parameters were never significantly $(\alpha=0.05)$ different from zero (results not shown), suggesting weak relationships. 
Table 5. Statistics of linear mixed models relating the growth efficiency index (GE) and three growth-based indices to state variables at tree and stand levels. All models also included an intercept, tree species (fixed effect), and a random site effect.

\begin{tabular}{cccccc}
\hline Dependent Variables & Independent Variables & AIC & $\boldsymbol{\Delta}_{\boldsymbol{i}}$ & $\boldsymbol{W}_{\boldsymbol{t}_{\boldsymbol{i}}}$ & $\boldsymbol{R}^{2}$ \\
\hline \multirow{2}{*}{$\mathrm{GE}$} & $\mathrm{RH}$ & 2327.5 & 0.0 & $9.5 \times 10^{-1}$ & 0.05 \\
& $\mathrm{CSA}+\mathrm{RH}$ & 2333.2 & 5.7 & $5.4 \times 10^{-2}$ & 0.11 \\
\hline \multirow{2}{*}{ BAI $_{-1-5}$} & $\mathrm{CSA}+\mathrm{RH}$ & 2943.9 & 0.0 & $1.0 \times 10^{-1}$ & 0.39 \\
& $\mathrm{CSA}$ & 2958.4 & 14.5 & $6.9 \times 10^{-4}$ & 0.38 \\
\hline \multirow{2}{*}{ BAI $_{-1-7}$} & $\mathrm{CSA}+\mathrm{RH}$ & 3139.9 & 0.0 & $1.0 \times 10^{-1}$ & 0.39 \\
& $\mathrm{CSA}$ & 3157.8 & 17.9 & $1.3 \times 10^{-4}$ & 0.37 \\
\hline \multirow{2}{*}{ BAI $_{-1-10}$} & CSA + RH & 3320.1 & 0.0 & $1.0 \times 10^{-1}$ & 0.37 \\
& CSA & 3339.8 & 19.7 & $5.5 \times 10^{-5}$ & 0.36 \\
\hline
\end{tabular}

Note: RH is tree relative height, CSA is the crown surface area, DBH is the diameter at breast height $(1.3 \mathrm{~m})$, and BA is stand basal area.

\section{Discussion}

\subsection{Relationships between Quantitative and Qualitative Tree Vigor Indices}

The principal objective of this study was to establish relationships between a system of tree vigor classification based upon apparent stem defects and some quantitative tree vigor indices to evaluate the ability of the former to identify low-vigor trees. A first relationship involved the growth efficiency index that expresses the amount of wood produced annually per unit leaf area. Because the allocation priority to stemwood is low in normally growing trees [12], a high value of this index suggests that tree carbon resources far exceed priority allocations, implying strong overall tree vigor [11]. Accordingly, this index successfully predicted the vigor and mortality probabilities of trees affected by defoliating and boring insects $[15-17,19]$. In our case, the growth efficiency index was not significantly related to the vigor classes that were based upon apparent stem defects, which is a first indication of the lack of reliability of the classification system for tree vigor evaluation.

To lend support to the preceding result, we used $\mathrm{BAI}_{-1-5}$, which is a growth-based index that is closely related to tree vigor classes (Table 3), to determine whether its temporal changes were related to changes in tree vigor classes. In focusing only upon tree vigor changes that were observed over time for the same trees, this analysis allowed us to remove a portion of the between-tree variation from the vigor class determinations, which can notably be influenced by tree hierarchical position $[35,36]$ and age [37]. Even when this inter-tree variation was removed, only $16 \%$ of vigorous trees that became non-vigorous $8-10$ years later could be correctly classified. Nevertheless, significant differences in BAI $_{-1-5}$ were detected between the two extreme classes (i.e., $\mathrm{M}$ and $\mathrm{R}$ classes), while the intermediate classes were not distinguished from the extreme classes. These results agree with those of Hartmann et al. [10] and Guillemette et al. [9], who significantly differentiated only classes $\mathrm{M}$ and $\mathrm{R}$ using a growth-based index to predict the mortality probability of sugar maple trees.

Overall, these results indicate that the apparent stem defects that were used in the tree classification system under study are weakly related, at best, to the actual vigor of sugar maple and yellow birch trees. Interestingly, Power and Havreljuk [38] observed a strong relationship between these vigor classes and stem quality classes that are commonly used in northeastern Canada [39]. This observation is likely related to the fact that the same stem defects are used in both classifications. Thus, it seems that despite being weak indicators of tree vigor, some of these apparent stem defects are useful for estimating the potential monetary value of hardwoods [2].

The tree vigor system under study is currently applied in northern hardwood stands to identify trees that would be harvested during partial cut operations and, consequently, to improve the vigor of future stands. Nevertheless, some observations suggest that the selection rules that are used by this classification system may not achieve the expected benefit. For example, Nolet et al. [40] observed that 
the proportion of moribund trees (M class) that was determined by the classification system increased with increasing site quality, while tree mortality that was measured 10 years after tree vigor class determination indicated the opposite trend. These conflicting results underscore the need that such a classification system for evaluating tree vigor should include variables other than those that represent only apparent stem defects. Additional potential variables could reflect past stand management practices, site quality, tree social status, stand density, and tree bark characteristics, among others [41]. Further, our results and those of Hartmann et al. [10] and Guillemette et al. [9] indicate that the use of intermediate vigor classes seems ambiguous in determining the vigor or the mortality probability of trees. Therefore, it is possible that simplifying the tree vigor system by eliminating intermediate classes could improve the tree marking process without affecting its quality. To this end, Cecil-Cockwell and Caspersen [42] proposed a parsimonious, three-class system that takes into account tree vigor and stem quality while eliminating superfluous classes that do not influence the value of sugar maple trees. Indeed, tree mortality of hardwood species was significantly related to a binary classification of tree vigor, whereas a two-class stem product system also contributed to tree mortality predictions [43], further suggesting that criteria for stem quality and tree vigor are frequently confounded.

\subsection{Possible Drawbacks of the Growth Efficiency Index}

The classification system under study reflects the probability of tree mortality during the upcoming cutting cycle, i.e., a 25-year period [28]. This includes mortality risks that are related to stem structural defects, such as leaning trees, stem base injuries, fork cracks and stem cracks [7]. These defects, especially when they are associated with decay, increase the risks of stem breakage that is caused by wind. Yet these defects do not necessarily affect the diameter growth and the vigor of trees [10], implying that growth efficiency and growth-based indices could be rather insensitive to these defects. Therefore, the lack of correspondence between these sources of mortality risk and tree diameter measurements could explain, in part, the weak relationship between vigor classes and the quantitative vigor indices.

The growth efficiency index has been used by several authors to evaluate the vigor of hardwood species (e.g., [44-46]), but some limitations regarding the use of this index should be considered for deciduous species. For instance, annual wood production of sugar maple seems less closely related to leaf area than what has been observed for most conifers [18]. This can be explained by the fact that unlike most conifers, hardwood species must produce new foliage each spring to activate the photosynthetic process. Because the production of this new foliage is related to the quantity of carbohydrates that is stored during previous years, wood production of hardwood species is more strongly dependent upon the growing conditions that prevailed during these years than are conifers [47]. Therefore, environmental factors such as drought, low temperature, or insect defoliation can influence tree growth for several years [18], especially in less vigorous trees [10]. These effects may thus contribute to explaining the weak relationship that was observed between the quantitative vigor indices and the vigor classes based upon apparent stem defects. To reduce these effects, it should be noted that tree diameter growth was averaged over a five-year period to avoid introducing effects of episodic events into the vigor indices.

\subsection{Estimating the Growth Efficiency Index from State Variables}

Because tree diameter growth is rarely available from usual forest inventory data, low-vigor trees are difficult to identify using the growth efficiency index or growth-based indices, which would benefit from being estimated from tree and stand state variables. Candidate variables that can be related to the growth efficiency index include stand density [15,16], tree social status [11,36], tree crown size [48], and tree diameter [49]. Yet, none of these variables allowed us to estimate adequately either the growth efficiency index or growth-based indices of sugar maple and yellow birch trees in the uneven-aged hardwood stands under study. The low predictive ability of our relationships may be partly explained by the exclusion from our sample of all trees with a DBH less than $20 \mathrm{~cm}$ and those that were neither 
dominant nor codominant. Nevertheless, better predictions of the growth efficiency index could be obtained by considering other state variables such as tree bark characteristics. Indeed, old trees often have rough bark [50], which could explain the significant relationship between bark appearance and diameter growth of sugar maple and yellow birch trees [41]. Between two trees of similar diameter, the one with the smoothest bark would be younger and faster growing than the one with the roughest bark. The possible relationship between bark appearance and the growth efficiency index is worth testing to help identify low-vigor trees more easily during tree marking operations in northern hardwood stands.

\section{Conclusions}

This study demonstrates that tree vigor classes that were deduced from apparent stem defects were weakly related to the growth efficiency index and other indices solely based upon tree diameter measurements. Since the development of a new vigor classification system is a long process, systems that are based upon apparent stem defects should continue to be used over the medium-term in order to improve the vigor of degraded northern hardwood stands. However, these systems would benefit from being simplified because their current complexity does not provide a gain in precision. In addition, a promising quantitative estimator of tree vigor, the growth efficiency index, was poorly related to usual characteristics of sugar maple and yellow birch trees. Further studies should be conducted in an attempt to relate the growth efficiency index to other tree characteristics, such as bark appearance, to increase our ability to distinguish vigorous from non-vigorous trees, and to identify the defects that actually reflect tree vigor and growth.

Author Contributions: E.M. performed the field and laboratory data collection, analyzed the data, and contributed to the study design and to the paper writing; S.B. provided past measurements from the Duchesnay experimental site, and contributed to the study design and to the paper writing; G.M. contributed to the fieldwork and to the paper writing; D.P. conceived the study, provided the funding of the project, and contributed to the data analysis and to the paper writing.

Funding: This research was funded by a Discovery Grant from the Natural Sciences and Engineering Research Council (NSERC) of Canada awarded to David Pothier.

Acknowledgments: We are grateful to Sharad Kumar Baral, Eloïse Dupuis, Alexandre Morin-Bernard, Félix Poulin, Corryne Vincent, Marie-Laure Lusignan, Émilie St-Jean, Pierre Racine, and Martine Lapointe for their help with the fieldwork and in the laboratory. We also thank William F.J. Parsons for reviewing and making valuable comments on the manuscript.

Conflicts of Interest: The authors declare no conflict of interest.

\section{References}

1. Delisle-Boulianne, S.; Fortin, M.; Achim, A.; Pothier, D. Modelling stem selection in northern hardwood stands: Assessing the effects of tree vigour and spatial correlations with a copula approach. Forestry 2014, 87, 607-617. [CrossRef]

2. Havreljuk, F.; Achim, A.; Auty, D.; Bédard, S.; Pothier, D. Integrating standing value estimations into tree marking guidelines to meet wood supply objectives. Can. J. For. Res. 2014, 44, 750-759. [CrossRef]

3. Pothier, D.; Fortin, M.; Auty, D.; Delisle-Boulianne, S.; Gagne, L.-V.; Achim, A. Improving tree selection for partial cutting through joint probability modeling of tree vigor and quality. Can. J. For. Res. 2013, 43, 288-298. [CrossRef]

4. Nyland, R.D. Selection system in northern hardwoods. J. For. 1998, 96, 18-21.

5. Guillemette, F.; Bédard, S.; Fortin, M. Evaluation of a tree classification system in relation to mortality risk in Québec northern hardwoods. For. Chron. 2008, 84, 886-899. [CrossRef]

6. Laliberté, J.; Pothier, D.; Achim, A. Adjusting harvest rules for red oak in selection cuts of Canadian northern hardwood forests. Forestry 2016, 89, 402-411. [CrossRef]

7. Boulet, B.; Landry, G. La Carie des Arbres: Fondements, Diagnostic et Application, 3rd ed.; Les Publications du Québec: Québec, QC, Canada, 2015; p. 372. 
8. Fortin, M.; Bédard, S.; Guillemette, F. Estimation par Simulation Monte Carlo de la Probabilité de Mortalité Quinquennale de L'érable à Sucre, du Bouleau Jaune et du Hêtre à Grandes Feuilles en Peuplements de Feuillus en Fonction de la Classification MSCR; Avis Technique; Gouvernement du Québec, Ministère des Ressources Naturelles et de la Faune, Direction de la Recherche Forestière: Québec, QC, Canada, 2008; p. 11.

9. Guillemette, F.; Bédard, S.; Havreljuk, F. Probabilités de Mortalité des Feuillus Selon le Classement de la Priorité de Récolte; Direction de la Recherche Forestière: Québec, QC, Canada, 2015; p. 11.

10. Hartmann, H.; Beaudet, M.; Messier, C. Using longitudinal survival probabilities to test field vigour estimates in sugar maple (Acer saccharum Marsh.). For. Ecol. Manag. 2008, 256, 1771-1779. [CrossRef]

11. Waring, R.H.; Thies, W.G.; Muscato, D. Stem growth per unit of leaf area: A measure of tree vigor. For. Sci. 1980, 26, 112-117.

12. Waring, R.H. Characteristics of trees predisposed to die. Bioscience 1987, 37, 569-574. [CrossRef]

13. Christiansen, E.; Waring, R.H.; Berryman, A.A. Resistance of conifers to bark beetle attack: Searching for general relationships. For. Ecol. Manag. 1987, 22, 89-106. [CrossRef]

14. Waring, R.H.; Newman, K.; Bell, J. Efficiency of tree crowns and stemwood production at different canopy leaf densities. Forestry 1981, 54, 129-137. [CrossRef]

15. Mitchell, R.G.; Waring, R.H.; Pitman, G.B. Thinning lodgepole pine increases tree vigor and resistance to mountain pine beetle. For. Sci. 1983, 29, 204-211.

16. Waring, R.H.; Pitman, G.B. Modifying lodgepole pine stands to change susceptibility to mountain pine beetle attack. Ecology 1985, 66, 889-897. [CrossRef]

17. Coops, N.C.; Waring, R.H.; Wulder, M.A.; White, J.C. Prediction and assessment of bark beetle-induced mortality of lodgepole pine using estimates of stand vigor derived from remotely sensed data. Remote Sens. Environ. 2009, 113, 1058-1066. [CrossRef]

18. Reed, D.D.; Pregitzer, K.S.; Liechty, H.; Burton, A.J.; Mroz, G.D. Productivity and growth efficiency in sugar maple forests. For. Ecol. Manag. 1994, 70, 319-327. [CrossRef]

19. Coyea, M.R.; Margolis, H.A. The historical reconstruction of growth efficiency and its relationship to tree mortality in balsam fir ecosystems affected by spruce budworm. Can. J. For. Res. 1994, 24, 2208-2221. [CrossRef]

20. Boivin-Dompierre, S.; Achim, A.; Pothier, D. Functional response of coniferous trees and stands to commercial thinning in eastern Canada. For. Ecol. Manag. 2017, 384, 6-16. [CrossRef]

21. Pedersen, B.S. Modeling tree mortality in response to short and long-term environmental stresses. Ecol. Model. 1998, 105, 347-351. [CrossRef]

22. Yao, X.; Titus, S.J.; MacDonald, S.E. A generalized logistic model of individual tree mortality for aspen, white spruce, and lodgepole pine in Alberta mixedwood forests. Can. J. For. Res. 2001, 31, 283-291. [CrossRef]

23. Bigler, C.; Bugmann, H. Growth-dependent tree mortality models based on tree rings. Can. J. For. Res. 2003, 33, 210-221. [CrossRef]

24. Duchesne, L.; Ouimet, R.; Morneau, C. Assessment of sugar maple health based on basal area growth pattern. Can. J. For. Res. 2003, 33, 2074-2080. [CrossRef]

25. Saucier, J.-P.; Grondin, P.; Robitaille, A.; Gosselin, J.; Morneau, C.; Richard, P.J.H.; Brisson, J.; Sirois, L.; Leduc, A.; Morin, H.; et al. Chapitre 4: Écologie forestière. In Manuel de Foresterie; Éditions MultiMondes: Montréal, QC, Canada, 2009; pp. 165-316.

26. Grondin, P.; Jean, N.; Hotte, D. Intégration de la Végétation et de ses Variables Explicatives à des Fins de Classification et de Cartographie D'unités Homogènes du Québec Meridional; Direction de la Recherche Forestière: Québec, QC, Canada, 2007; p. 62.

27. Russell, M.B.; Weiskittel, A.R. Maximum and largest crown width equations for 15 tree species in Maine. North. J. Appl. For. 2011, 28, 84-91.

28. Boulet, B. Défauts Externes et Indices de la Carie des Arbres; Les Publications du Québec: Québec, QC, Canada, 2007; p. 291.

29. Lambert, M.-C.; Ung, C.-H.; Raulier, F. Canadian national tree aboveground biomass equations. Can. J. For. Res. 2005, 35, 1996-2018. [CrossRef]

30. Moreau, E.; Bédard, S.; Baral, S.K.; Pothier, D. Evaluating electrical resistivity tomography to estimate sapwood area and leaf area of sugar maple and yellow birch. Ecohydrology 2018, e2014. [CrossRef] 
31. Pinheiro, J.; Bates, D.; DebRoy, S.; Sarkar, D.; R Core Team. Nlme: Linear and Nonlinear Mixed Effects Models. R Package Version 3.1-137. 2018. Available online: https:/ /CRAN.R-project.org / package=nlme (accessed on 21 September 2018).

32. Burnham, K.P.; Anderson, D.R. Model Selection and Multimodel Inference: A Practical Information-Theoretic Approach, 2nd ed.; Springer: New York, NY, USA, 2002; p. 488.

33. Mazerolle, M.J. Improving data analysis in herpetology: Using Akaike's information criterion (AIC) to assess the strength of biological hypotheses. Amphibia-Reptilia 2006, 27, 169-180. [CrossRef]

34. Fawcett, T. ROC Graphs: Notes and Practical Considerations for Researchers; Technical Report HPL-2003-4; HP Laboratories: Palo Alto, CA, USA, 2004.

35. Maguire, D.A.; Brissette, J.C.; Gu, L.H. Crown structure and growth efficiency of red spruce in uneven-aged, mixed-species stands in Maine. Can. J. For. Res. 1998, 28, 1233-1240. [CrossRef]

36. Ryan, M.G.; Phillips, N.; Bond, B.J. The hydraulic limitation hypothesis revisited. Plant Cell Environ. 2006, 29, 367-381. [CrossRef] [PubMed]

37. Seymour, R.S.; Kenefic, L.S. Influence of age on growth efficiency of Tsuga canadensis and Picea rubens trees in mixed-species, multiaged northern conifer stands. Can. J. For. Res. 2002, 32, 2032-2042. [CrossRef]

38. Power, H.; Havreljuk, P. Predicting hardwood quality and its evolution over time in Quebec's forests. Forestry 2018, 91, 259-270. [CrossRef]

39. Petro, F.J.; Calvert, W.W. La Classification des Billes de Bois Francs Destinées au Sciage; Forintek Canada Corp.: Ottawa, ON, Canada, 1990.

40. Nolet, P.; Hartmann, H.; Bouffard, D.; Doyon, F. Predicted and observed sugar maple mortality in relation to site quality indicators. North. J. Appl. For. 2007, 24, 258-264.

41. Gauthier, M.-M.; Guillemette, F. Bark type reflects growth potential of yellow birch and sugar maple at the northern limit of their range. Plant Ecol. 2017, 219, 381-390. [CrossRef]

42. Cecil-Cockwell, M.J.L.; Caspersen, J.P. A simple system for classifying sugar maple vigour and quality. Can. J. For. Res. 2015, 45, 900-909. [CrossRef]

43. Fortin, D.; Bédard, S.; DeBlois, J.; Meunier, S. Predicting individual tree mortality in northern hardwood stands under uneven-aged management in southern Québec, Canada. Ann. For. Sci. 2008, 65, 205. [CrossRef]

44. Allen, C.B.; Will, R.E.; Jacobson, M.A. Production efficiency and radiation use efficiency of four tree species receiving irrigation and fertilization. For. Sci. 2005, 51, 556-569.

45. Binkley, D.; Stape, J.L.; Bauerle, W.L.; Ryan, M.G. Explaining growth of individual trees: Light interception and efficiency of light use by Eucalyptus at four sites in Brazil. For. Ecol. Manag. 2010, 259, 1695-1703. [CrossRef]

46. Voelker, S.L.; Lachenbruch, B.; Meinzer, F.C.; Kitin, P.; Strauss, S.H. Transgenic poplars with reduced lignin show impaired xylem conductivity, growth efficiency and survival. Plant Cell Environ. 2011, 34, 655-668. [CrossRef] [PubMed]

47. Lane, C.J.; Reed, D.D.; Mroz, G.D.; Liechty, H.O. Width of sugar maple (Acer saccharum) tree rings as affected by climate. Can. J. For. Res. 1993, 23, 2370-2375. [CrossRef]

48. Zarnoch, S.J.; Bechtold, W.A.; Stolte, K.W. Using crown condition variables as indicators of forest health. Can. J. For. Res. 2004, 34, 1057-1070. [CrossRef]

49. Binkley, D.; Stape, J.L.; Ryan, M.G.; Barnard, H.R.; Fownes, J.H. Age-related decline in forest ecosystem growth: An individual-tree, stand-structure hypothesis. Ecosystems 2002, 5, 58-67. [CrossRef]

50. Clausen, K.E.; Godman, R.M. Bark Characteristics Indicate Age and Growth Rate of Yellow Birch; Research Note NC-75; U.S. Department of Agriculture, Forest Service, North Central Forest Experimental Station: St. Paul, MN, USA, 1969.

(C) 2018 by the authors. Licensee MDPI, Basel, Switzerland. This article is an open access article distributed under the terms and conditions of the Creative Commons Attribution (CC BY) license (http:/ / creativecommons.org/licenses/by/4.0/). 